\title{
O discurso da gestão democrática na Revista Brasileira de Política e Administração da Educação (1995-2004)
}

\author{
The discourse of democratic management in the Brazilian Journal of Policy \\ and Management of Education (1995-2004) \\ El discurso de la gestión democrática en la Revista Brasileira de Política e \\ Administração da Educação (1995-2004) \\ ANA LUCIA CALBAISER DA SILVA \\ JAIME FARIAS \\ JOSÉ CARLOS ROTHEN
}

Resumo: Este estudo buscou investigar a participação da Revista Brasileira de Política e Administração da Educação (RBPAE) na construção do discurso educacional brasileiro, a partir da análise dos artigos publicados nessa revista no período de 1995 a 2004. A metodologia pautou-se pela articulação da bibliometria com a análise do discurso foucaultiana. A RBPAE foi considerada, neste estudo, como veículo de divulgação científica que participou do processo de dispersão do discurso educacional por meio da preponderância do discurso da gestão democrática.

Palavras-chave: Revista Brasileira de Política e Administração da Educação (RBPAE); discurso educacional; gestão democrática.

\begin{abstract}
This study aimed to investigate the participation of the Brazilian Journal of Policy and Management of Education (RBPAE) in the construction of the Brazilian "educational discourse" from the analysis of the articles published in this journal from 1995 to 2004. The methodology is based on the link between the bibliometrics and Foucault's discourse analysis. In this study, RBPAE was considered as a science communication vehicle that participated in the dispersion process of the "educational discourse" through the preponderance of the discourse of democratic management.
\end{abstract}

Keywords: Brazilian Journal of Policy and Management of Education (RBPAE); educational discourse; democratic management.

Resumen: Este estudio buscó investigar la participación de la Revista Brasileña de Política y Administración de la Educación (RBPAE) en la construcción del discurso educativo brasileño, a partir del análisis de los artículos publicados en esa revista en el período de 1995 y 2004. La metodología se basa en la articulación de bibliométricos con el análisis del discurso de Foucault. La RBPAE fue considerada en este estudio, como vehículo de divulgación científica que participó en el proceso de dispersión del discurso educativo a través de la preponderancia del discurso de la gestión democrática.

Palabras clave: Revista Brasileña de Política y Administración de la Educación (RBPAE); discurso educativo; gestión democrática. 


\section{INTRODUÇÃO}

Na área educacional, o processo histórico dos estudos sobre administração, gestão democrática e gerencialismo está atrelado às formas de compreender a organização das instituições, sobretudo as públicas. As investigações sobre administração da educação pública brasileira ganharam maior expressão a partir da década de 1930; no período anterior, foram poucos os trabalhos teóricos e de sistematização do conhecimento a tratar especificamente sobre administração da educação (SANDER, 2007).

Os acontecimentos que se deram a partir da década de 1930 foram importantes para o processo de desenvolvimento de estudos da área. Nesse contexto, destaca-se o fim da República Velha, a permanência de políticas pautadas no discurso nacionalista, a centralização administrativa do Estado Novo e o desenvolvimento de políticas intervencionistas na economia (CUNHA, 1989). Analisando esse período, Dermeval Saviani (2010) aponta que o processo de industrialização e de modernização marcou profundamente a sociedade brasileira. A educação escolar, por sua vez, incorporou as demandas dessa nova realidade, considerando a expansão e as transformações do mercado de trabalho.

Segundo Benno Sander (1981), o processo de desenvolvimento desse campo de estudos ocorreu sob uma relação de interdependência entre Administração Pública e Administração da Educação. Para a administração pública educacional do país, houve a adoção de estudos realizados em âmbito internacional, como os princípios da administração científica de Frederick Taylor, industrial de Henri Fayol, e burocrática de Max Weber. Uma das justificações para a adoção dos princípios da administração científica na administração pública pautou-se pela consideração de que, embora primordialmente pensados para a organização empresarial capitalista, estes princípios não se restringiriam às organizações lucrativas.

A aproximação entre administração empresarial e administração escolar teve sentidos distintos para teóricos de cada área. Maria de Fátima Costa Félix (1986) destaca que, no ponto de vista de teóricos da Administração de Empresas, os princípios da Teoria Geral da Administração (TGA), elaborados primordialmente para as empresas, poderiam ser generalizados para organizações cuja finalidade não fosse lucrativa, como é o caso das instituições públicas educacionais. Já para teóricos da Administração Escolar, a aproximação entre administração empresarial e administração escolar pautou-se pela busca da cientificidade por meio da validação de seus princípios por teorias da administração de empresas. Tais teorias permitiriam o alcance de eficiência e de racionalidade que outras organizações,, como as empresas, já haviam alcançado.

682 - RBPAE - v. 31, n. 3, p. 681 - 696 set./dez. 2015 
O estudo sobre gestão democrática na área da educação ganhou forte expressão na década de 1980, momento em que o país passava por um processo de redemocratização política. A busca por uma gestão democrática passou a fazer parte da reivindicação dos movimentos sociais do período. A possibilidade de participação da comunidade nas tomadas de decisão, a descentralização da estrutura educacional por meio da municipalização, a busca por uma escola que atendesse a todos, foram algumas das bandeiras levantadas naquele contexto (RISCAL, 2009).

A inserção do princípio de gestão democrática na Constituição Federal de 1988 foi uma das conquistas desses movimentos. Embora houvesse empecilhos para a realização plena da gestão democrática no interior da escola, como, por exemplo, a falta de uma cultura participativa, espaços foram abertos para que ocorresse a participação da comunidade nos processos de tomada de decisão. Convém ressaltar que o exercício participativo no interior da escola é compreendido por alguns estudiosos como aprendizagem para a cidadania na sociedade democrática (DOURADO, 2005, GOHN, 2006).

$\mathrm{Na}$ produção científica da área, esse contexto trouxe maiores discussões sobre a administração pública que, na concepção de alguns autores, sob forma hierárquica, refletia o autoritarismo presente no Estado. Questionou-se a forma burocrática como a educação estava organizada nos diversos níveis. O termo gestão, nesse momento, passa a ser mais frequente nos estudos realizados na área. Enquanto a sociedade civil organizada lutava por gestão democrática na educação, as políticas públicas tendiam a implantar um projeto gerencialista. Tal projeto ganhou notoriedade com a Reforma Gerencial do Estado realizado no primeiro governo de Fernando Henrique Cardoso (1995-1998). De acordo com os princípios do gerencialismo, pautado pela lógica da mundialização, globalização e neoliberalismo, o Estado passaria a ser "agente efetivo de regulação do mercado e de capacitação das empresas no processo competitivo internacional” (BRESSERPEREIRA, 2001, p. 22).

Observando o modelo de gestão gerencialista realizado no Brasil, Fernando Luiz Abrucio (2010) destaca que suas principais bases foram: (a) democratização acompanhada por princípios de legalidade e publicidade, que tendem a garantir o fortalecimento de controle externo; (b) descentralização, em resposta, principalmente, ao regime centralizado do período militar; (c) profissionalização da burocracia por meio de capacitação dos servidores e concursos públicos.

Nesse período, diversos estudiosos passaram a questionar o gerencialismo, buscando compreender seus conceitos, sua relação com a educação e com a sociedade capitalista. Para isso, buscaram-se na literatura internacional aspectos 
teórico-metodológicos que possibilitassem ampliar o conhecimento sobre gerencialismo (CASASSUS, 2001; RISCAL, 2009).

Conforme visto acima, a discussão sobre aspectos organizacionais da educação pública brasileira esteve relacionada a três concepções de organização institucional, cada uma delas com maior preponderância em determinado contexto histórico. Essas concepções podem ser representadas por meio de três conceitos: administração, gestão democrática e gerencialismo. Cada um desses termos representa uma tendência geral em determinado momento, tanto no que se refere às práticas organizacionais quanto à produção do conhecimento. Contudo, cabe ressaltar que as três concepções mencionadas acima não designam formas puras de organização: existem entrecruzamentos entre elas. Portanto, uma determinada concepção organizacional pode apresentar características em comum com outra(s).

Considerando tais questões, este artigo tem como objetivo apresentar aspectos da construção do "discurso educacional" sobre administração, gestão democrática e gerencialismo no meio acadêmico. Para isso, elegeram-se como objeto de pesquisa os artigos publicados na Revista Brasileira de Política e Administração da Educação (RBPAE) no período de 1995 a 2004.

\section{O ESTUDO DA RBPAE: CONSTRUINDO CAMINHOS, APONTANDO DISCURSOS}

A RBPAE ${ }^{1}$, um dos periódicos científicos da Associação Nacional de Política e Administração da Educação (ANPAE), surgiu em 1983 como um projeto de divulgação científica na área de política e de gestão da educação. Para Sander (1983), a criação da Revista representou para a ANPAE uma forma de concretizar seus objetivos institucionais.

Segundo Gilson Ricardo Medeiros Pereira e Maria da Conceição Lima de Andrade (2007), no período de criação da RBPAE, os programas de pós-graduação em educação estavam em processo de consolidação nas universidades brasileiras. Tal fato possibilitou aumento considerável na produção e divulgação de pesquisas acadêmicas e, consequentemente, a criação de uma rede de periódicos voltados para a educação. Percebe-se, nesse instante, que a criação da RBPAE reflete esse movimento, propiciando à ANPAE maior participação no âmbito das discussões teóricas e práticas na área da política e administração da educação.

\footnotetext{
1 Desde sua fundação em 1983 até o ano de 1995, o periódico analisado era denominado Revista Brasileira de Administração da Educação. A partir de 1996, passou a ser intitulado Revista Brasileira de Política e Administração da Educação. Neste artigo adota-se esta última denominação como referência a ambos os períodos.
}

684 - RBPAE - v. 31, n. 3, p. 681 - 696 set./dez. 2015 
Maria Beatriz Moreira Luce, que foi designada para o cargo de editor, foi a responsável pela elaboração do projeto inicial e lançamento da Revista. Relatando a história da criação da RBPAE, Luce (2001, p. 141) aponta que:

\footnotetext{
O início de nossa Revista foi motivado pela noção de que, por força da qualificação de especialistas, então habilitados nos cursos de Pedagogia, havia demanda por um periódico semestral que promovesse a sua educação continuada e também, de outra parte, pela noção de que a expansão da pós-graduação e da pesquisa no país, já proporcionava massa crítica suficiente para que à diretoria fossem submetidos artigos em quantidade e qualidade que permitissem uma rigorosa seleção de matérias.
}

Dessa forma, a RBPAE surgiu como espaço de qualificação profissional e de socialização de conhecimentos produzidos pela comunidade científica, contando com o apoio intelectual de pesquisadores e de pós-graduados que poderiam submeter artigos à Revista. Além disso, considerou-se que a produção e socialização dos saberes poderiam ser realizadas pela própria elite intelectual brasileira, que não precisaria mais recorrer apenas à importação de conhecimentos ou restringir-se aos conhecimentos disponíveis em suas próprias Instituições de Ensino Superior. A RBPAE oportunizaria o intercâmbio entre pesquisadores da área (SILVA, 2012).

Considerando o contexto histórico em que a RBPAE é constituída, percebe-se que esse periódico acompanhou o processo de redemocratização da sociedade brasileira e de Reforma Administrativa do Estado, realizada, conforme vimos acima, no primeiro governo de Fernando Henrique Cardoso. Nesse contexto, as discussões sobre gestão pública ganharam destaque, em especial nos debates no campo da educação. Segundo Silva (op. cit.), "a Revista reflete o movimento que as organizações públicas de ensino sofreram, iniciando pela discussão sobre administração da educação, perpassando pelo processo de definição e luta pela gestão democrática, e apresentando discussões tanto pró quanto contra o gerencialismo" (p. 126).

Enquanto meio de divulgação científica do campo educacional, são expressos na RBPAE opiniões, discussões, denúncias da realidade e projeções sobre o papel da administração e da gestão no processo de melhoria da qualidade da educação brasileira.

\section{ASPECTOS METODOLÓGICOS}

Este trabalho consiste em uma pesquisa bibliográfica que utiliza artigos da RBPAE como fonte para o estudo do discurso da comunidade acadêmica 
sobre administração, gestão e gerencialismo. A análise dos artigos publicados nesse periódico é compreendida, neste estudo, como possibilidade de interpretar a relação desse veículo com a comunidade científica. Isso ocorreu pelo levantamento da sua produção, o que permitiu identificar aspectos relacionados à autoria dos artigos. De passagem, a identidade dos autores não foi propriamente o objeto deste estudo, haja vista que a função autor, na perspectiva foucaultiana, é "característica do modo de existência, de circulação e de funcionamento de certos discursos no interior de uma sociedade" (FOUCAULT, 2006, p. 274). Em outras palavras, o que se buscou não foi atribuir uma singularidade aos autores, mas, sim, compreender sua ligação com o espaço de produção de discursos. Nesse contexto, o autor não cria enunciados, mas assume determinada posição na rede de relações de poder por onde circulam estratégias e discursos que compõem a comunidade científica.

Para cumprir os objetivos mencionados, a análise dos artigos foi realizada, inicialmente, por meio de estudo bibliométrico. Esse procedimento originou um banco de dados na forma de uma planilha eletrônica, contendo elementos coletados nos artigos da RBPAE (título, autor, ano etc.). A partir dessa documentação, as informações foram organizadas segundo critérios quantitativos. Essas informações permitiram a construção de categorias baseadas na frequência de expressões encontradas em seus títulos, escolhidas como objeto de estudo as seguintes: administração da educação, gestão democrática, gerencialismo.

Por meio dessa categorização, percebeu-se a alteração no discurso educacional. Conforme Silva (2012, p. 13), houve uma descontinuidade em relação ao uso das categorias supracitadas no período de 1995 a 2004. Até então, a expressão Administração da Educação era a mais utilizada; contudo, sua frequência decresce a partir de 1995, quando o termo Gestão torna-se mais frequente nos títulos dos artigos. Nesse mesmo período, em função da ampliação da discussão sobre gestão, ganha maior espaço um conjunto de conceitos atribuídos ao gerencialismo. A partir disso, delimitou-se o corpus da investigação nos 38 artigos publicados no período de 1995 a 2004, que mencionaram em seus títulos as categorias administração da educação, gestão democrática e termos relacionados ao gerencialismo (gestão estratégica, gestão inovadora).

Convém ressaltar que a utilização da bibliometria não está isenta de críticas. Estas estão relacionadas, principalmente, a sua associação à ciência positivista. Isto se dá pela utilização de ferramentas matemáticas e estatísticas, conforme indica Maria Cristina Piumbato Innocentini Hayashi et al. (2007). Para superar esses limites, incorporaram-se, nesta investigação, elementos metodológicos da chamada Análise Foucaultiana do Discurso (FLICK, 2009, p. 304). 
A relação entre bibliometria e os estudos foucaultianos (em especial, a arqueologia do saber) baseia-se na proposta teórico-metodológica de Lídia Alvarenga (1998). A autora pretende ampliar as possibilidades de análise dos dados empíricos levantados pela bibliometria a partir de uma abordagem dialógica. Isso significa que dados quantitativos propiciam interpretações não apenas sobre aspectos discursivos mais frequentes e evidentes, mas também sobre aqueles que estão ocultos e/ou indeterminados.

Para a autora, a relação entre bibliometria e arqueologia do saber ocorre por meio de pressupostos como:

\begin{abstract}
1) a bibliometria e a arqueologia do saber são disciplinas que têm como objeto comum os discursos formadores de um campo de conhecimento;2) a literatura que forma uma área de conhecimento é polifônica, dispersa, descontínua, intertextual e dependente de estratégias persuasivas e pragmáticas, estas estreitamente dependentes das posições de poder ocupadas por seus produtores; 3) o processo de produção de conhecimento depende de estratégias persuasivas e pragmáticas decorrentes das aspirações de poder e interesse inerentes ao comportamento dos autores; 4) os estudos bibliométricos, caracterizando-se especialmente por sua base empírica, são passíveis de fornecer subsídios concretos e sistematizados para estudos arqueológicos, evidenciando entre ambos os campos uma relação de complementaridade (ALVARENGA, 1998, p. 253).
\end{abstract}

A partir disso, verifica-se que a bibliometria e a arqueologia do saber são concepções que podem complementar-se, permitindo uma exploração mais abrangente dos dados. Nesse sentido, apresenta-se, a seguir, o estudo bibliométrico que serve como referência à investigação do discurso educacional veiculado na Revista.

\title{
OS AUTORES E O DISCURSO EDUCACIONAL NA RBPAE
}

O termo discurso, na acepção aqui utilizada, refere-se ao "conjunto dos enunciados que provém de um mesmo sistema de formação" (FOUCAULT, 1972, p. 135). A relação dos autores com a Revista é mediada, portanto, por um conjunto de enunciados específicos - mas não permanentes. Esses enunciados, à medida que são definidos por certas regras de formação, constituem as condições de existência dos discursos (op. cit.). É nesse sentido que o discurso é analisado, não para encontrar algo que seria seu ponto de origem, mas para compreendê-lo em sua dispersão. Para isso, busca-se identificar as regularidades de determinada formação discursiva e as condições que tornam possível a circulação de certos discursos (e a consequente interdição ou desvalorização de outros). Desse modo, verifica-se que a Revista participa da construção de um discurso educacional. A partir 
das informações obtidas por meio da análise dos artigos selecionados, buscou-se identificar aspectos relacionados aos autores desses artigos e sua participação na formação desse discurso.

Em primeiro lugar, o discurso educacional construído na Revista está vinculado à administração, mesmo porque esse é seu foco, em termos editoriais. Contudo, o termo gestão tem sido muito utilizado no meio educacional atualmente. Essa tendência é verificada na Revista, conforme os dados coletados. Entre 1995 e 2004, foram publicados 38 artigos que continham em seus títulos os termos administração (12 artigos) e gestão (26 artigos). Após leitura e análise, esses estudos foram classificados nas seguintes categorias: administração da educação (dez artigos), gestão democrática (22 artigos) e gerencialismo (seis artigos).

Verificou-se que eses artigos apresentaram 46 autores diferentes; apenas três deles estiveram presentes em mais de uma publicação ${ }^{2}$. Por esses dados, percebe-se que a Revista desenvolveu, nesse período, uma política editorial que permitiu a inserção de novos autores e não apenas a publicação de artigos de autores já incluídos em outras edições. Com isso, pode-se afirmar que diferentes autores contribuíram para a formação do discurso sobre gestão democrática na RBPAE. Pode-se, também, afirmar que, na seleção de artigos, a política editorial da Revista não esteve baseada em critérios de escolha por afinidade pessoal e/ou status.

Para verificar aspectos mais específicos relacionados à autoria dos artigos investigados foram coletadas informações disponíveis na plataforma do Currículo Lattes $^{3}$ dos autores. É importante ressaltar que nesse momento foram selecionadas apenas as informações referentes ao ano em que o artigo foi publicado. Com base nos apontamentos disponibilizados nessa plataforma, foi construída a Tabela 1, na qual se observa a titulação dos autores que publicaram os artigos selecionados.

Tabela 1: Titulação acadêmica dos autores

\begin{tabular}{|c|c|c|}
\hline TITULAÇÃO ACADÊMICA & TOTAL & PORCENTAGEM \\
\hline Livre-Docência & 2 & $4,3 \%$ \\
\hline Pós-Doutorado & 7 & $15,2 \%$ \\
\hline Doutorado & 16 & $34,8 \%$ \\
\hline Doutorando & 6 & $13,1 \%$ \\
\hline
\end{tabular}

\footnotetext{
2 A disparidade entre o número de autores (46) e o número de artigos (38) publicados explica-se pela questão de haver trabalhos em coautoria.

3 Para a obtenção de dados referentes ao Currículo Lattes dos autores, foi consultado o site http:// lattes.cnpq.br/, que possui um banco de dados com o currículo dos autores. A alimentação desse banco de dados é realizada pelos próprios autores.
}

688 - RBPAE - v. 31, n. 3, p. 681 - 696 set./dez. 2015 
Tabela 1: Titulação acadêmica dos autores

\begin{tabular}{|c|c|c|}
\hline TITULAÇÃO ACADÊMICA & TOTAL & PORCENTAGEM \\
\hline Mestrado & 4 & $8,7 \%$ \\
\hline Mestrando & 1 & $2,2 \%$ \\
\hline Especialização & 2 & $4,3 \%$ \\
\hline Graduando & 1 & $2,2 \%$ \\
\hline Não Informado & 7 & $15,2 \%$ \\
\hline Total Geral & 46 & $100 \%$ \\
\hline
\end{tabular}

Fonte: SILVA, Ana Lúcia Calbaiser (2012).

Os autores com nível de pós-graduação (Livre-Docência, Pós-Doutorado, Doutorado, Doutorando, Mestrado, Mestrando, Especialização) corresponderam a $82,6 \%$, sendo a maior incidência o nível Doutorado, com 34,8\%. Considerando que os autores dos artigos também são leitores da Revista, percebe-se que a circulação dos discursos dispostos no periódico ocorreu, especialmente, entre os pós-graduados. A Revista, portanto, apresentou considerável inserção no meio acadêmico, principalmente, em programas de pós-graduação, constituindo-se como um dos veículos de divulgação da comunidade científica.

Quanto à área de atuação dos autores ${ }^{4}$, a investigação explicitou as possíveis relações entre os campos de conhecimento dos autores dos artigos selecionados, conforme a tabela abaixo.

Tabela 2: Área de atuação do autor

\begin{tabular}{|c|c|c|}
\hline Área de atuação & Total & Porcentagem \\
\hline Administração & 1 & $2,2 \%$ \\
\hline Ciências Sociais & 2 & $4,3 \%$ \\
\hline Educação & 32 & $69,5 \%$ \\
\hline Educação Especial & 1 & $2,2 \%$ \\
\hline Filosofia & 1 & $2,2 \%$ \\
\hline Gestão Educacional & 1 & $2,2 \%$ \\
\hline Pedagogia & 1 & $2,2 \%$ \\
\hline Não informado & 7 & $15,2 \%$ \\
\hline Total geral & 46 & $100 \%$ \\
\hline
\end{tabular}

Fonte: SILVA, Ana Lúcia Calbaiser 2012.

$\mathrm{Na}$ Tabela 2, verifica-se que todos os autores atuavam em áreas relacionadas às Ciências Humanas. A grande maioria deles afirmou pertencer à área da Educação (69,5\%). Percebe-se, também, que autores de áreas distintas

4 Estas informações também foram coletadas no Currículo Lattes dos autores. 
(porém não distantes) da Educação, como Filosofia, colaboraram, eventualmente, com a circulação do discurso educacional na RBPAE. Nota-se, portanto, que essas são áreas correlatas, cujas discussões teóricas podem aproximar-se da Educação.

Conforme visto acima, a análise da distribuição do discurso educacional na teia de relações que compõem a comunidade científica presente na Revista, formada, principalmente, por pós-graduados da área da Educação, destaca que a categoria gestão democrática foi mais frequente nos artigos pesquisados. Em razão disso, realiza-se, a seguir, a análise dessa categoria como aspecto preponderante no discurso veiculado na revista.

\section{DISCURSO EDUCACIONAL: GESTÃO DEMOCRÁTICA}

Tendo em vista os aspectos apontados anteriormente, sobre o modo como se organiza a produção científica na RBPAE, é possível ampliar o entendimento sobre as relações de poder presentes na formação dos discursos que envolvem a comunidade científica e a sociedade. Conforme indica Foucault (2004), "em toda sociedade a produção do discurso é ao mesmo tempo controlada, selecionada, organizada e redistribuída por certo número de procedimentos" (p. 8-9), sendo que esses mecanismos de controle delimitariam o discurso aceitável em determinado contexto.

Assim, é importante dimensionar as diversas teorias que influenciam as relações sociais. Uma dessas teorias, presente com maior frequência na RBPAE, conforme visto acima, é a da gestão democrática. A análise dos artigos indica que os autores tendem a apresentar essa teoria de modo prescritivo. Pouco se discutem, portanto, os fundamentos filosóficos da gestão democrática, mas se a enfatiza como ideal a ser alcançado. Nesse sentido, o conjunto de artigos investigados demonstra uma orientação política da Revista e, também, uma forma de esta inserir se na comunidade científica. Ao veicular, em sua maioria, estudos voltados à prescrição, a Revista participa do processo de afirmação do discurso da gestão democrática no âmbito da formação do discurso educacional.

Analisando os pressupostos foucaultianos, Gary Radford (apud ALVARENGA, 1998) aponta que a participação de atores sociais na afirmação de discursos é um dado fundamental para a estruturação e delineação do conhecimento científico, pois esse "repousaria sobre um suporte institucional, sendo reforçado e acompanhado por outros estratos e práticas sociais” (p. 255). A partir da constatação dessa dinâmica, é possível pensar na circulação dos discursos presentes na sociedade, por meio de instrumentos como os periódicos de divulgação científica. Essa circulação possibilita a coexistência, a confrontação e a ocultação de teorias na comunidade científica. Convém ressaltar que as

690 - RBPAE - v. 31, n. 3, p. 681 - 696 set./dez. 2015 
teorias não deixam de existir por causa dessa dinâmica; contudo, dependendo do contexto, algumas são mais evidentes que outras.

Considerando a incidência das teorias veiculadas nos artigos da Revista, percebe-se que uma das razões para a forte presença de discursos em prol da gestão democrática é sua linha editorial. Essa linha busca contribuir para a "produção e socialização do conhecimento no campo das políticas públicas e da gestão democrática da educação no Brasil" (FARENZENA; LUCE; SANDER, 2009, p. 7).

Sendo a Revista um veículo de divulgação científica, existe uma lógica interna que norteia sua política editorial, a qual influencia na seleção de artigos e, consequentemente, de discursos veiculados. Essa seleção está relacionada a sua linha editorial, que se vincula aos fatores externos e internos. No caso da RBPAE, destacam-se fatores como a legislação educacional, que regulamenta a organização da educação pública, pautada na gestão democrática, além dos interesses da própria mantenedora da Revista, a ANPAE, que visa a constituir-se como fórum de discussão sobre temas relacionados à administração e às políticas educacionais. A Revista, portanto, representa a confluência dessas relações de poder que se estabelecem no âmbito da produção científica e, com base nisso, estabelece um conjunto de normas e valores que regem seu funcionamento e são necessários a sua inserção na cultura acadêmica (MIRANDA; PEREIRA, 1996). Além disso, é importante salientar que a participação no circuito dos impressos científicos demanda seu reconhecimento institucional por parte da sociedade, ou pelo menos, dos leitores e possíveis autores.

Desse modo, as práticas de submissão de artigos estão relacionadas à lógica interna e externa da RBPAE, conforme mencionado acima. Para Dely Bezerra de Miranda e Maria de Nazaré Freitas Pereira (op.cit), os possíveis autores submetem artigos com orientação próxima ao que "imaginam” ser a linha editorial da Revista, buscando reduzir as possibilidades de rejeição dos trabalhos.

Convém ressaltar que, no contexto brasileiro, o discurso da gestão democrática foi amplamente defendido no processo de abertura política pós-regime militar e consolidou-se por meio do preceito constitucional da "gestão democrática do ensino público" (BRASIL, 1988). Com isso, a Revista tende a colaborar com o processo de implantação e implementação de políticas fundamentadas no referido discurso.

Nota-se que na RBPAE, além do discurso sobre gestão democrática, foram publicados estudos sobre gerencialismo, em menor quantidade, porém. Alguns desses artigos pautaram-se por críticas a essa concepção teórica. De acordo com Sandra Aparecida Riscal (2009) uma das razões da resistência ao uso do discurso gerencialista na educação brasileira pauta-se pelo caráter hierarquizante e 
centralizador que o termo gerencialismo possui. No senso comum, esse conceito está fortemente relacionado ao poder pessoal e individual e, segundo essa linha de pensamento, tal relação de poder poderia restringir a participação coletiva.

Verifica-se que os artigos relacionados ao discurso gerencialista não se distanciam, em geral, do discurso da gestão democrática, uma vez que aquele é apresentado de maneira crítica. Pode-se mesmo considerar que essa crítica ao gerencialismo reafirma grande parte dos enunciados fundamentais da gestão democrática.

\section{CONCLUSÃO}

Neste trabalho, buscou-se evidenciar alguns aspectos subjacentes à produção científica, especificamente à produção veiculada por uma revista reconhecida no meio acadêmico: a RBPAE. Outrossim, significou elucidar, num certo nível, as relações construídas dentro de um regime de verdade.

Considerando que a circulação de discursos ocorre por meio de autores e, na Revista, também pela ação de editores, buscou-se compreender aspectos da formação desses discursos. Para tanto, foram analisadas questões relacionadas à autoria dos artigos, no sentido de identificar a inserção dos autores na comunidade científica no momento em que publicaram seus artigos. Com esse propósito, investigou-se a titulação acadêmica deses autores e sua área de atuação. Constatou-se que a grande maioria era formada por autores pós-graduados, o que indica que a Revista pôde contar com o apoio de pesquisadores dese nível acadêmico para a submissão de artigos, alcançando um dos propósitos dispostos em seu projeto editorial. Sobre a área de atuação, notou-se que, embora a maioria dos autores estivesse ligada à Educação, o discurso educacional constituiu-se também pela participação de autores de outras áreas do conhecimento. Isso possibilitou a ampliação da circulação desse discurso em distintas áreas da comunidade científica.

Além disso, foram apontados alguns aspectos que corroboraram a inserção da RBPAE na comunidade científica. Tais aspectos foram relacionados à compreensão da frequência com que os termos administração, gestão e gerencialismo apareceram nos títulos dos artigos. A partir dos dados bibliométricos sobre essa produção, foram estabelecidos como período de análise os anos de 1995 a 2004, quando houve uma mudança na ênfase dos discursos veiculados na Revista. Os artigos que continham em seus títulos o termo administração tornaram-se menos frequentes em relação aos que continham o termo gestão, e os artigos com termos relacionados a gerencialismo começam a ganhar espaço na Revista.

Quanto à orientação da política editorial, verificou-se que o discurso

692 - RBPAE - v. 31, n. 3, p. 681 - 696 set./dez. 2015 
educacional está majoritariamente relacionado, na Revista, ao discurso sobre gestão democrática, a partir das relações de poder subjacentes às práticas editoriais. Segundo Foucault (1995), a preponderância de um discurso supõe uma relação de poder que não é simples imposição ou consentimento, mas depende dos efeitos, reações e respostas mútuas: é uma ação de um sobre a ação do outro. Dessa forma, a presença, embora reduzida, de artigos sobre gerencialismo configura-se na estratégia de afirmação do discurso preponderante no periódico, que é o da gestão democrática.

Por meio deste estudo foi possível perceber que a produção do discurso educacional não é uma prática exclusiva da RBPAE. Essa Revista apresenta-se como veículo de divulgação no cenário científico, abrindo espaço para a participação de atores sociais que compõem a comunidade científica, colaborando, ambos, para a construção discursiva sobre a gestão democrática da educação brasileira.

\section{REFERÊNCIAS}

ABRUCIO, Fernando Luiz. Desafios contemporâneos para a reforma da administração pública. In: PETERS, B. Guy; PIERRE, Jon. (Org.). Administração pública: coletânea. Trad. Sonia Midori Yamamoto, Mirian Oliveira. São Paulo: Editora UNESP; Brasília, DF: ENAP, 2010. p. 537-548.

ALVARENGA, Lídia. Bibliometria e arqueologia do saber de Michel Foucault traços de identidade teórico-metodológica. Ciência da Informação. v. 27, n. 3, p. 253-261. 1998.

BRASIL. Presidência da República. Casa Civil. Subchefia para Assuntos Jurídicos. Constituição da República Federativa do Brasil de 1988. Brasília: Senado Federal, 1988. Disponível em: <http://www. planalto.gov.br/ccivil_03/ constituicao/constitui\%c3\%a7ao.htm>. Acesso em: 16 mar. 2011.

BRESSER-PEREIRA, Luiz Carlos. Do Estado Patrimonial ao Gerencial. In: SACHS, Ignacy; WIHEIM, Jorge; PINHEIRO, Paulo Sérgio (Org.). Brasil: um século de transformações. São Paulo: Companhia das Letras, 2001. p. 222-259. Disponível em: <http:/ /www.bresserpereira. org.br/view.asp?cod=509>. Acesso em :22 abr. 2011.

CASASSUS, Juan. A reforma educacional na América Latina no contexto de globalização. Tradução de Luiz Pontual. Cadernos de Pesquisa. n. 114, p. 7-28, 
nov. 2001. Disponível em: <www.scielo.br/pdf/cp/n114/a01n114.pdf>. Acesso em: 06 jun. 2011.

CUNHA, Célio da. Educação e autoritarismo no estado novo. 2. ed. São Paulo: Cortez, 1989. (Coleção Educação Contemporânea. Série Memória da Educação).

DOURADO, Luiz Fernando. Gestão democrática da educação e mecanismo de participação coletiva. Debate: retrato da escola. Ministério da Educação. Salto para o Futuro; TV Escola: Boletim 12, jun./jul. p. 27-30, 2005.. Disponível em: <tvbrasil.org.br/fotos/salto/series/150822 RetratosEscola.pdf>. Acesso em: 05 jun. 2011.

FARENZENA, Nalú; LUCE, Maria Beatriz; SANDER, Benno. RBPAE, 25 anos de caminhada: e a trilha continua [Editorial]. Revista Brasileira de Política e Administração da Educação, v. 25, n. 1, p. 7-10, jan./abr. 2009.

FÉLIX, Maria de Fátima Costa. Administração escolar: um problema educativo ou empresarial. 3. ed. São Paulo: Cortez: Autores Associados, 1986. (Coleção Educação Contemporânea).

FLICK, Uwe. Introdução à pesquisa qualitativa. Trad. Joice Elias Costa. $3^{\mathrm{a}} \mathrm{ed}$. Porto Alegre: Artmed, 2009.

FOUCAULT, Michel. Estética: literatura e pintura, música e cinema. 2. ed. Organização e seleção de textos de Manuel Barros da Motta. Trad. Inês Autran Dourado Barbosa. Rio de Janeiro: Forense Universitária, 2006. (Coleção Ditos e Escritos III).

. A ordem do discurso: aula inaugural no Collège de France, pronunciada em 2 de dezembro de 1970. 10ª ed. Trad. Laura Fraga de Almeida Sampaio. São Paulo: Loyola, 2004.

. O sujeito e o poder. In: DREYFUS, Hubert L.; RABINOW, Paul. Foucault: uma trajetória filosófica: para além do estruturalismo e da hermenêutica. Trad. Vera Porto Carrero. Rio de Janeiro: Forense Universitária, 1995. p. 231-249.

A arqueologia do saber. Trad. Luiz Felipe Baeta Neves. Revisão de Lígia Vassalo. Petrópolis, RJ: Vozes; Lisboa: Centro do Livro Brasileiro, 1972. 
GOHN, Maria da Glória. Educação Não-formal, Participação da Sociedade Civil e Estruturas Colegiadas nas Escolas. Ensaio: avaliação e políticas públicas em educação. Rio de Janeiro, v. 14, n. 50, p. 27-38, jan./mar. 2006. Disponível em: $\quad<$ http://www.scielo.br/scielo.php?script $=$ sci_ $\quad$ arttext\&pid=S0104$40362006000100003 \&$ lang=pt>. Acesso em: 04 jun. 2011.

HAYASHI, Maria Cristina Piumbato Innocentini. et al. Um estudo bibliométrico sobre a educação jesuítica no Brasil colonial. Biblios: Revista de Bibliotecologia y Ciencias de La Información. Lima, v. 8, n. 27, p. 1-18, 2007.

LUCE, Maria Beatriz Moreira. Editorial [Editorial]. Revista Brasileira de Política e Administração da Educação, v. 17, n. 2, p. 141-144, jul./dez. 2001.

MIRANDA, Dely Bezerra de; PEREIRA, Maria de Nazaré Freitas. O periódico científico como veículo de comunicação: uma revisão de literatura. Ciência da Informação, v. 25, n. 3, p. 375 382, set./dez. 1996. Disponível em: <http:// revista.ibict.br/cienciadainformacao/index.php/ciinf/ article/view/462/421>. Acesso em: 21 mar. 2012.

PEREIRA, Gilson Ricardo Medeiros; ANDRADE, Maria da Conceição Lima de. A construção da administração da educação na RBAE (1983-1996). Revista Brasileira de Política e Administração da Educação (RBPAE), Porto Alegre, v. 23, n. 1, p. 137-151, jan./abr. 2007.

REVISTA BRASILEIRA DE ADMINISTRAÇÃO DA EDUCAÇÃO. Janeiro de 1995 a dezembro de 1995.

REVISTA BRASILEIRA DE POLÍTICA E ADMINISTRAÇÃO DA EDUCAÇÃO. Janeiro de 1996 a dezembro de 2005.

RISCAL, Sandra Aparecida. Gestão democrática no cotidiano escolar. São Carlos: EdUFSCar, 2009. (Coleção UAB-UFSCar).

SANDER, Benno. Administração da educação no Brasil: genealogia do conhecimento. Brasília: Liber Livro, 2007

- Apresentação. Revista Brasileira de Administração da Educação, v. 1, n. 1, p. 7-8, jan./jun. 1983. 
Administração da Educação no Brasil: evolução do conhecimento. Fortaleza: Edições UFC; Brasília, DF, Associação Nacional de Profissionais de Administração da Educação, 1981. (Série Cadernos de Administração Escolar, VII).

SÁ-SILVA, Jackson Ronie; ALMEIDA; Cristóvão Domingos de; GUINDANI; Joel Felipe. Pesquisa educacional: pistas teórias e metodológicas. Revista Brasileira de História \& Ciências Sociais, ano 1, n. 1, p. 1-15, jul. 2009. Disponível em: <<http://www.rbhcs.com/ index_arquivos/Artigo.Pesquisa\%20 documental.pdf $>>$. Acesso em: 07 maio 2014.

SAVIANI, Dermeval. História das idéias pedagógicas no Brasil. 3. ed. Campinas: Autores Associados, 2010. (Coleção memória da educação).

SILVA, Ana Lúcia Calbaiser da. Encruzilhadas da organização educacional: conceito de administração, de gestão e de gerencialismo na RBPAE. 2012. 184 f. Dissertação (Mestrado em Educação) - Universidade Federal de São Carlos. São Carlos: UFSCar, 2012.

ANA LÚCIA CALBAISER DA SILVA é doutoranda em Educação pela Universidade Federal de São Carlos - UFSCar. Atualmente é professora na Escola Superior de Tecnologia e Educação de Porto Ferreira - Asser Porto Ferreira. E-mail: anacalbaiser@yahoo.com.br

JAIME FARIAS é doutor em Educação pela Universidade Federal de São Carlos - UFSCar. Atualmente é professor do Curso de Pós-Graduação Lato Sensu em Coordenação Pedagógica da UFSCar. E-mail: jaimefarias@uol.com.br

JOSÉ CARLOS ROTHEN é doutor em Educação pela Universidade Metodista de Piracicaba. Atualmente é professor adjunto do Departamento de Educação da Universidade Federal de São Carlos. E-mail: jcr3219@yahoo.com.br

Recebido em novembro de 2015

Aprovado em dezembro de 2015 